\title{
Notas sobre \\ Ana Hatherly e Fernando Pessoa
}

\author{
Fernando Martinho \\ Universidade de Lisboa
}

RESUMO: O PRESENTE TRABALHO VISA ESTUDAR OS CAMINHOS QUE ASSUME, NA OBRA DE ANA HATHERLY, O SEU DIÁLOGO COM PESSOA, NÃO MOTIVADO POR QUALQUER CONTINUIDADE EPIGONAL, MAS PELO ANSEIO DE DEFINIÇÃO DE NOVOS OBJECTIVOS E DE PRODUÇÃO DE NOVOS SENTIDOS.

ABSTRACT: THE ARTICLE AIMS AT STUDYING THE DIALOGUE OF ANA HATHERLY'S POETRY WITH PESSOA. ANA HATHERLY'S ORIGINALITY COMES OUT FROM THAT DIALOGUE. IN FACT PESSOA GIVES HER THE OPPORTUNITY OF MAKING SOME OF THE FUNDAMENTAL ISSUES OF HER COMPLEX POETICAL WORK CLEARER.

PALAVRAS-CHAVE: ANA HATHERLY - FERNANDO PESSOA - DIÁLOGO INTERTEXTUAL - MODERNISMO - EXPERIMENTALISMO

KEY-WORDS: ANA HATHERLY - FERNANDO PESSOA - INTERTEXTUAL DIALOGUE MODERNISM - EXPERIMENTALISM 
ue Pessoa foi, para a poesia portuguesa do século XX, mais um ponto de partida do que um ponto de chegada, ao contrário do que uma ou outra voz minoritária chegou a expressar, prova-o a abundância e a fundura do diálogo que, dos mais diversos modos, suscitou a muitos dos poetas que vieram depois. A razão, a esse respeito, não é difícil constatá-lo, está do lado dos que pensam, como Eduardo Lourenço, que considera não ser possível escrever poesia como se a sua experiência não tivesse ocorrido, ou, como Ruy Belo, que a poesia portuguesa era uma coisa e passou a ser diferente depois de Fernando Pessoa. Ana Hatherly é, desde muito cedo, um dos poetas, entre nós, que nele viram um ponto de viragem e tomaram o seu exemplo como uma forma de libertação, de definição criativa do seu próprio percurso. $\mathrm{O}$ que, em 1975, num inquérito da Colóquio/Letras, disse a propósito do "significado do histórico do Orpheu" poderia, sem esforço, aplicar-se ao que, para ela, significou aquele que foi indubitavelmente a figura central desse momento inaugural do nosso Modernismo:

[...] se fosse necessário falar da influência directa das obras que escreveram os poetas dominantes do Orpheu, eu diria que, quando, numa determinada zona da criatividade, se atinge com uma obra ou um grupo de obras uma realização inultrapassável dentro do seu próprio espaço, a partir daí todas as verdadeiras tentativas criadoras se voltam sempre para novos objectivos, novos sentidos. ${ }^{1}$

Essas palavras, escritas num momento de plena afirmação do vanguardismo da autora, ajudam-nos a compreender, como teremos ocasião de observar, os caminhos inesperados que, em alguns casos, assume o seu diálogo com Pessoa, em claro desvio do estímulo inicial, e motivado não por qualquer continuidade epigonal, mas pelo anseio de definição de "novos objectivos" e de produção de "novos sentidos".

$\mathrm{Na}$ fase inicial de Ana Hatherly, que corresponde aos livros publicados em finais da década de 50, que é, em termos da recepção activa de Pessoa, a década pessoana por excelência, percebe-se que é o Pessoa das contradições e dos paradoxos que mais lhe interessa, vindo muito ao encontro do que é, então, uma orientação barroquizante com forte implantação junto dos poetas

“O significado histórico do Orphen (195-1975)". Lisboa: Colóquio-Letras, 1975. p. 8. 
mais jovens. A sombra do Pessoa de "Autopsicografia" e "Isto", inexcedível mestre de agudęas em volta das relações paradoxais entre dores sentidas e dores fingidas, verdade e mentira, paira em poemas de $A$ dama e o cavaleiro, 1960 (“O termo que eu temo / Em mim estremece. / Não é o que passa / Nem aquilo que esquece / Que o meu ser receia / É antes / Essa dor contínua / Que de si mesma se torna cadeia. / Se alguma dor existe / Que o termo não atinja, / Não existe porém termo algum / Que a própria dor não finja: / Sentes? Mentes. / Sabes? Não vês. / Quando descobres, passaste / Quando interpretas / Esqueces."), e de As aparências, 1959 ("Com o mesmo nome, / Com as mesmas palavras e com igual sabor, / $\mathrm{O}$ mesmo motivo produz efeito inverso. / Aquilo que hoje eleva / Logo afunda; / Aquele que promete / E logo se desmente, / Só diz que do presente / O querer é já ausente, / E não mentira: / Apenas a verdade que não sente...”). No posfácio à terceira edição da novela O Mestre, 1995, a própria autora escreverá, ainda dentro da mesma linha da relação dialéctica fição/verdade, interiorizada pela literatura portuguesa pós-Pessoa e que Eugénio de Andrade sintetizará na fórmula feliz da "ficção da verdade", que "a ficção é um mundo tão real como o outro, porque a mentira da ficção não é o oposto da verdade". Por outro lado, o famoso verso inaugural de "Autopsicografia", no seu modelo frásico, será, na poesia de Ana Hatherly, como veremos, propulsor de novas formulações, respondendo a outros "objectivos", apontando a outros "sentidos": vide, por exemplo, "Um calculador de improbabilidades" ("O poeta é / um calculador de improbabilidades [...]", "Poemas de Sigma e contemporâneos", de 1965, em Um calculador de improbabilidades, 2001) e "O poeta é um guardador", de $O$ cisne intacto, 1983.

$\mathrm{Na}$ nota crítico-biobliográfica que acompanha a apresentação dos poemas de Ana Hatherly no volume II das Líricas portuguesas, 1983, refere-se Jorge de Sena à presença da "tradição sintáctica de Álvaro de Campos" na poesia da autora de Eros frenético, a partir de Sigma. Estando genericamente de acordo com Sena, eu estenderia, no entanto, essa tradição sintáctica a um versilibrismo mais amplo, em que, no que diz respeito aos poetas mais informados, e assumidamente cosmopolitas (veja-se, por exemplo, o gosto pela utilização da Sprachmischung num poema como "Litoteana", vindo a público no no 2 do magazine de poesia e desenho Nova, outono de 1976), como é o caso de Ana Hatherly, confluem outros veios, nomeadamente os do modernismo anglo- 
americano. Embora, na inevitável síntese da sua nota, Sena não mencione expressamente ocorrências de um específico diálogo intertextual com Álvaro de Campos, a convocação do heterónimo de Pessoa faz, aí, todo o sentido. Com efeito, esse diálogo é bem sensível no tríptico de Eros frenético, "Noite canto-te noite", "Canto-te" e "Noite Noite", e a própria autora o assume no "Roteiro" com que faz anteceder a publicação dos seus poemas experimentais no já referido Um calculador de improbabilidades. O estímulo, colheu-o Ana Hatherly naquele que será um dos poemas de Pessoa mais glosados pelos seus herdeiros, a "Ode à noite", o que fica bem patente, para não irmos mais longe, nos seguintes versos: "E tudo morre quando tu chegas/ E tudo se dilui e se transforma em ti" (cf. os versos de Campos, no final da ode: "Todos os sons soam de outra maneira / Quando tu vens. / Quando tu entras baixam todas as vozes, / Ninguém te vê entrar. / Ninguém sabe quando entraste, / Senão de repente, vendo que tudo se recolhe, / Que tudo perde as arestas e as cores [...]"). Como noutro lugar tive oportunidade de dizer, a propósito desta série de poemas, o segundo texto, em que o lexema 'noite' é rasurado, constitui uma 'variação' do primeiro, e o terceiro recolhe o lexema suprimido no segundo, nas mesmas posições em que ocorria no primeiro"2. No "Roteiro" a que acima se fez referência, esclarece a autora que o tríptico "ilustra um tipo de experimentação sobre o silêncio, que tem a ver com a [sua] íntima ligação com a música, inclusive com a música de vanguarda", falando também de uma "exploração do silêncio no texto através de uma escrita lacunar, já iniciada" na série "Noite canto-te noite". Escusado me parece realçar a pertinência de tal experimentação sobre o silêncio com relação a um texto que, no plano semântico, como se sabe, plenamente o identificava com a entidade insistentemente invocada pelo sujeito na ode de Campos.

Se são nítidos, conforme observa a autora no "Roteiro", os "ecos pessoanos" num poema como "A chuva oblíqua é um convite à inclinação do teu ombro" ("Poemas de Sigma e contemporâneos", de 1965, em Um calculador de improbabilidades, 2001), pelo menos no que tange ao título, já o mesmo se não verifica relativamente a um texto como "Príncipe" (ibid.). Neste último caso, dificilmente o leitor se daria conta da sua relação intertextual com o poema $\mathrm{XX}$ de $\mathrm{O}$ guardador de rebanhos, "O Tejo é mais belo que o rio que corre pela

2 Cf. Pessoa e a moderna poesia portuguesa - do "Orpheu" a 1960, 2. ed., 1991. 
minha aldeia" (objecto, registe-se, de minuciosa análise no mais conhecido dos textos que Ana Hatherly criticamente dedicou a Pessoa, "O cubo das sensações e outras práticas sensacionistas em Alberto Caeiro”, O espaço crítico, 1979), se não dispusesse desta informação extratextual. Só a partir das pistas sugeridas o leitor se apercebe de que a estrutura dos textos é semelhante, assente na repetição com variação e no paradoxo. Quanto ao resto, o poema de Ana Hatherly, enveredando deliberadamente pelos caminhos de um erotismo moderno, com laivos de um romantismo passional, afasta-se inequivocamente do texto que lhe teria servido de ponto de partida, muito mais interessado, esse, na expressão polémica dos pontos de vista do seu autor ficcional, obsessivamente apostado em demonstrar as vantagens do seu pequeno mundo natural sobre as grandezas do outro conformado pelo discurso da cultura. Já no caso de "A chuva oblíqua é um convite à inclinação do teu ombro", um poema em prosa, trata-se essencialmente de um exercício irónico de aplicação do princípio estruturante do ismo pessoano de menor eco na poesia sua contemporânea ou subseqüente, o interseccionismo, ao topos das relações entre o homem e a máquina, até ao ponto em que os papéis de um e de outra se tornam permutáveis:

Com o decorrer do tempo e pela assimilação do ruído pelo universo musical, a identidade do homem com a máquina foi-se estreitando de tal modo que um dia começou a desenvolver-se entre os dois uma função humoral muito particular que permitiu que um dia nascesse à máquina mais um braço extremamente fino e resistente e, durante uma passagem indicada na partitura com uma designação dinâmica apropriada, o homem e a máquina se envolvessem num amoroso amplexo. Foi então que se revelou o poder criador da máquina que entrara pela cabeça dentro da máquina./ Na verdade nesse dia a máquina conseguiu emitir um sonido totalmente diferente dos habituais e previstos na partitura:/ no momento em que ia pronunciar a primeira palavra, riu.

Percebe-se também que - independentemente dos ecos mais sensíveis que haja, no texto em apreço, da sequência de poemas interseccionistas "Chuva oblíqua", nomeadamente do seu último poema, por intermédio de signos como "maestro" ou "partitura" - o que sobretudo fascina Ana Hatherly é o seu carácter experimental, programático (vide o que se diz no prefácio a Um 
calculador de improbabilidades sobre a relevância do "programa" nos poemas experimentais), vindo, por aí, ao encontro das preocupações de vanguarda que são, então, eminentemente as da autora.

O poema "Um calculador de improbabilidades", que faz parte do mesmo grupo de meados dos anos 60 e que é um dos exemplos de adopção do modelo frásico do verso inaugural de "Autopsicografia" para que oportunamente chamámos a atenção, testemunha igualmente o "fascínio" de Ana Hatherly e dos seus companheiros na aventura experimentalista pela ciência, surgindo, no seu caso, o "maquinal" associado ao erótico, como se lembra no "Roteiro”. Como também, aí, se salienta, o recurso à terminologia científica no discurso poético, e de que um dos exemplos mais notórios será, na circunstância, a utilização do termo "polímeros", obedece claramente a propósitos de subversão do "cânone lírico tradicional", numa época em que, na literatura nacional, a convocação da linguagem científica à poesia se limitava praticamente a alguns textos de António Gedeão, respeitadores, em outros aspectos, daquele cânone, e quando ainda haveria que esperar uma meia dúzia de anos pelas experiências mais ousadas de Limite de idade, de Vitorino Nemésio. Seja como for, a produtividade (e a rara felicidade) da formulação de Ana Hatherly ("O poeta é um calculador de improbabilidades"), e é isso que, para o tema que estamos a tratar, a sua relação com Pessoa, essencialmente nos interessa, deriva em larga medida do entendimento que faz do verso inicial de "Autopsicografia" como portador de uma irrevogável suspeita lançada sobre uma concepção de poesia certeiramente verberada por Eliot como "um soltar da emoção", e de que toda uma poética da modernidade assente na indeterminação e, poderíamos dizer mesmo, na improbabilidade, fez uma das suas mais agitadas bandeiras.

O próximo exemplo de utilização do modelo frásico do verso de abertura de "Autopsicografia", um poema breve que faz parte de O cisne intacto, de 1983, situa-se claramente depois do que a autora, nas "Notas para uma teoria do poema-ensaio", incluídas no fim do volume, considera ter sido o "delírio simultaneamente negativista e dionisíaco que marcou o [seu] trabalho durante a (longa) fase experimental" e dos "excessos revolucionários" que a acompanharam. O volume em questão corresponderia, ainda segundo Ana Hatherly, a "um re-pensar" da poesia que então se fazia, e, naturalmente, também da sua própria poesia, que envereda pelos caminhos da "depuração". Com efeito, os 
poemas de $O$ cisne intacto, embora coligidos em Um calculador de probabilidades, que, como se diz no prefácio, selecciona, dentro da sua obra e até 1989, o que "se pode incluir na categoria genericamente designada por poemas experimentais", representam uma mudança de rumo relativamente à radicalidade da fase anterior, ilustrada, por exemplo, pelos dois últimos textos que analisámos. $\mathrm{O}$ poema a que palimpsesticamente subjaz a "Autopsicografia" e em que, de algum modo, também ecoa o título do livro de Caeiro ("o poeta é um guardador // guarda a diferença / guarda da indiferença / / no incerto / guarda a certeza da voz"), é, como o texto que usa como ponto de partida, uma arte poética, orientada, no entanto, num outro sentido. No seu recorte extremamente depurado, a exigir a cooperação do leitor no completamento dos blanks a que aludem as "notas" incluídas no fim do volume, o poema, enquanto apresentação de uma poética, centra-se num dos papéis atribuídos ao poeta, como aquele cuja tarefa consiste em preservar, em guardar: a singularidade da sua voz na tradição ou tradições em que se insere, a capacidade de seduzir os que se aproximam dessa sua voz, de assegurar a partilha do que diz, e de afirmar a permanência da poesia no meio da incerteza, da impermanência da vida.

No sentido de uma cada vez maior limpidez se orientam os poemas de $A$ idade da escrita, de 1998, que vamos, agora, considerar e em que se encontram discretas alusões a textos e temas de Pessoa. Integrados num livro colocado, como o título de imediato sugere, sob clave metapoética, contêm na sua memória reminiscências do plurímodo texto pessoano, tantas vezes, como é sabido, propenso a acolher no seu seio a reflexão sobre o próprio acto poético. Em "A máscara da palavra", há ecos de uma conhecida passagem de "Tabacaria" (compare-se este passo: "Paraíso acidental / metódico exercício / a máscara da palavra / colou-se-nos ao rosto: / agora é / o nosso mais vital artifício" com o seguinte do poema de Pessoa: "Quando quis tirar a máscara, / estava pegada à cara”), associando, no entanto, segundo pode ver-se, a máscara mais à palavra do que ao poeta. Em "No fundo azul", a reminiscência pessoana procede mais uma vez dos textos em que se explicita a poética do fingimento, e o equacionar das relações entre a ficção e a verdade (" $\mathrm{Na}$ sensual tranquilidade da palavra / o poeta tenta uma arriscada ordem / e entre a fábula e a reportagem / simula mentir / para atingir / a superior verdade") não anda longe da formulação para que chamámos a atenção no posfácio da autora à terceira edição da novela O Mestre. Já em "Falo do que é físico", 
o que ecoa nos seguintes versos - "Pensando em tudo isso / extremamente sobreposto / como se uma grande dor não anulasse outra / como se fosse possível / pensar em mais de uma coisa de uma só vez / sentindo o simultâneo impossível / querendo abranger / a incontrolável voracidade dentro de tudo" - é uma das passagens do Campos de um dos fragmentos de "Passagem das horas" que os poetas portugueses melhor interiorizaram ("Sentir tudo de todas as maneiras, / Viver tudo de todos os lados, / Ser a mesma coisa de todos os modos possíveis ao mesmo tempo, / Realizar em si toda a humanidade de todos os momentos / Num só momento difuso, profuso, completo e longínquo").

Nas variações que Ana Hatherly realizou sobre as elegias de Rilke, em Rilkeana, 1999, porventura o ponto culminante de um programa aplicado com rara persistência a diversos autores ao longo dos anos (Camões, Joyce, Donne), a certa altura, mais concretamente na variação inicial sobre a famosa primeira das Elegias de Duino, distingue-se nitidamente um eco da "Ode à noite" de Campos, a pôr, afinal, em evidência que a memória literária só pode ser entendida como uma rede intertextual de múltiplas, intrincadas e, muitas vezes, imprevisíveis direcções: "Encostada à minha janela / contemplo a vossa beleza / que a todo o instante / se faz e se desfaz / até o chumbo da sombra avançar / e aos poucos surgir a noite / antiga e idêntica sempre / lançandome em vossos braços / vazios / cheios só de vozes / inaudíveis".

Naquelas que são as recolhas poéticas de Ana Hatherly de mais recente publicação, ambas de 2003, Itinerários e O pavão negro, se não considerarmos o caso especial da "plaquette" Fibrilações, de que foi feita, em 2004, uma edição de circulação restrita, vamos encontrar diálogos explicitamente assumidos com Pessoa, dentro, aliás, de uma linha decididamente intertextualista, muito em sintonia com o culturalismo da poesia portuguesa dos últimos anos. $\mathrm{Na}$ primeira colectânea, o que temos é uma glosa irónica, bem-humorada, desprendida, como convinha à circunstância, de um mote dado para um "magusto poético" no Palácio Fronteira, em Lisboa, em 1996, um mote retirado do famoso poema de Ricardo Reis "Os jogadores de xadrez" (Um púcaro com vinho refrescava/ Sobriamente a sua sede), colocado, como é sabido, sob o signo de Epicuro, expressamente invocado na sua segunda parte:

Um púcaro com vinho / por favor, trazei-me sem demora / que a sede já me mata e me devora / neste poético magusto / em que participo a tanto 
custo // A sede de poemas é insana / e co'aqueles que aflige tão tirana / que muitos pereceram na gincana // Por isso, por favor, p'ra meu refresco / trazei-me vinho / ou água simplesmente / que / se não sair daqui poema ingente / possa ao menos eu sair sobriamente...

Em "Quase écloga" de O pavão negro, um poema dedicado a Caeiro e em que o Mestre é tomado como destinatário da fala do sujeito poético, o diálogo com o heterónimo pessoano, "um poeta bucólico, de espécie complicada", conforme consta na famosa carta a Casais Monteiro de 13/1/1935, passa fundamentalmente pelo IX poema de O guardador de rebanhos ("Sou um guardador de rebanhos. / O rebanho é os meus pensamentos / E os meus pensamentos são todos sensações"). A ficção bucólica, de que Ana Hatherly, à semelhança de Caeiro, está bem consciente, e daí a suspeita assumida no advérbio do título, orienta-se num outro sentido, num livro, de resto, dominado pela reflexão sobre a escrita, o de associar as "ovelhas" não aos "pensamentos" que são "sensações", mas sim às "palavras", fazendo ainda derivar o poema, na sua parte final, para uma desenganada meditação sobre a morte, distante, na sua formulação alegorizante, do universo poético do dedicatário:

Olha: / também eu / sou pastor de rebanhos / e / iguais às tuas / as minhas ovelhas / também são palavras // Como sempre acontece / levamonos: / mutuamente nos apascentamos / numa contemplação / onde cintila a semelhança // Porém: / onde é que / de facto / cintila a semelhança? // Os fantasmas / dos heróicos cantores / jazem agora / no além-mistério / onde vive o dragão-lobo / que nenhum cão detém.

Reservei, para o fim, as Tisanas, textos em regra muito breves e de índole diversa - reflexões, anotações diarísticas, relatos, poemas em prosa -, que, como deixei dito noutro lugar", exigem do leitor "um subtil exercício de inteligência, que, ao mesmo tempo, requer a desaprendizagem das categorias lógicas habituais e a imersão em novas formas de apreensão da realidade que têm a ver com a sabedoria veiculada pelo Budismo Zen, designadamente pelos koans, ou seja, os problemas, os enigmas de que os mestres do Zen se servem para iniciação dos discípulos". Autêntico work in progress, que Ana Hatherly vem publicando desde os anos 60 , apresentam-se na sua edição mais recente com o título de 371 Tisanas, (2006). Dado o lugar que o humor, a ironia e o

Cf. n. 4 de Hablar/ Falar de Poesia, 2001. 
paradoxo ocupam nessas parábolas, seria de prever a irrupção de Pessoa nos mundos que elas constroem, tanto mais que há uma linha na tradição crítica pessoana, pelo menos desde os anos 70, e em que sobressaem nomes como os de Armando Martins Janeira, Leyla Perrone-Moisés e Onésimo Teotónio Almeida, intentando uma aproximação entre Caeiro e o Budismo Zen.

Numa das tisanas, a 114, a evocação de Pessoa vem associada a lugares míticos da sua peregrinação lisboeta, a Praça do Comércio e o café Martinho da Arcada, nela situado. Mas tanto ou mais que o cenário terá contribuído para desencadear a lembrança de Pessoa a disposição melancólica e depressiva do sujeito, que a proximidade da noite propicia: "Estou na arcada da velha praça é quase noite. O tráfego está no auge. Estou perto do café que Fernando Pessoa frequentava. Olho o céu e digo parece de papel pardo. Encosto-me a uma das colunas. Penso e repenso o suicídio diário. Estou triste. Não posso amar senão em liberdade". Numa outra, a 230, estamos perante uma brevíssima meditação sobre um retrato de Pessoa, não sabemos se feito pela própria autora. Não importa; é o retratado que está, aqui, em primeiro plano, sempre em processo de despersonalização, de se outrar: "Retrato de Fernando Pessoa: Sempre de perfil. A caminho da invisibilidade. Perdido na escrita, na entrada em outro". Um pouco à frente, na 234, o mal-estar do sujeito, a sua solidão, as dificuldades de relacionamento com os outros, dão azo a que encontre em Pessoa, mestre dos sentimentos contraditórios, um termo de comparação: "Hoje sinto-me realmente sem ninguém. Mas o motivo é que eu não estou capaz de fornecer aos outros os elementos necessários para que me restituam o que é meu. Como Pessoa, também eu sinto-o-que-não-sinto”. Finalmente, na tisana 269, o ponto de partida para o texto, muito próximo da anotação diarística, é a abertura da Casa Fernando Pessoa em Lisboa, na primeira metade dos anos 90. As notas mais impressivas do fragmento estarão, porventura, na reacção do sujeito perante a solução arquitectónica encontrada para a casa, que a teria destituído "literalmente" da alma, e na observação da cena, entre o pungente e o grotesco, de um actor disfarçado de Pessoa reclamando um impossível regresso a casa: "Abriu a casa de Fernando Pessoa. Lisboa em peso está presente, acotovelando-se nos corredores dessa instalação literalmente desalmada. Perturbada saio rapidamente. Do lado de fora, ainda desapercebido, um actor vestido à la Pessoa anos 30, roçando-se pela parede, diz baixinho: quero ir p'ra casa, quero ir p'ra casa". Numa pergunta acerca das Tisanas incluída numa en- 
trevista que me concedeu em 2001, disse Ana Hatherly: "O que acontece em todas, e isso é o que as torna fiéis ao princípio do Koan, é que há sempre um acontecimento. Acontece sempre alguma coisa, nem que o acontecimento seja apenas puramente linguístico, e, portanto, uma colecção de desafios...". Acontecimento ou desafio decisivo no percurso literário de Ana Hatherly, foi-o, de diversos modos, conforme pudemos ver, Fernando Pessoa, ele que, como se diz num texto de Anacrusa - 68 Sonhos, de 1983, sobre ela se terá projectado "como se fosse uma sombra ou uma nuvem", não certamente para a tolher, mas para a si própria, em total liberdade, a devolver. 